Tomasz Matyja

\title{
ASSESSMENT OF THE PALLET UNIT LOAD STABILITY BY SIMULATION METHODS
}

The paper presents a simulation model of a loading unit dynamics, with a layered structure, wrapped with a stretch film. Stretch film wrapping is the most commonly used and cheap method of securing the load unit. The model, proposed by the author, allows assessing the stability of the unit during the transport operations, when the loading unit is subjected to inertial forces. Deformations of a unit and prediction of its disintegration in extreme cases can be evaluated based on results of a simulation. The value of the necessary containment force as well as the number of wraps with the pre-stretched film, can also be estimated. In effect, simulations can reduce the amount of film used and the number of stability tests performed experimentally.

Keywords: load unit, stability, stretch film

\section{Introduction}

In the supply chain, a unit load is understood as a single mass that can be easily stored, mechanically stacked and moved between the two locations [1]. A load unit is usually made up of a series of smaller loads that are properly integrated and secured against disintegration. The pallet is the most commonly used platform for forming load units, which facilitates the transportation and storage of broadly understood material goods. Wrapping the unit load with the stretch film is the most frequently used method of protecting it against disintegration. The main advantage of the stretch film is its very low weight compared to the weight of the load and the fact that it is possible to apply the film both manually and mechanically using wrappers. The force bonding the whole load, called in the literature the containment force, is created by suitable pre-stretching the stretch film [2]. Of course, the more film layers the greater the force will be. However, the use of excessive numbers of layers unnecessarily increases packaging costs, contributes to redundant waste production and negatively affects the environment. Due to huge amounts of the stretch film used worldwide, it is important to apply the film as optimally as possible.

Pallet load units are classified into three classes due to the shapes of packages from which the unit is formed and their dimensional adjustment to the size of the pallet surface. Class A pallet units are made of identical packages, stacked in columns or bridges, which perfectly fill the surface of the pallet. The load on the A-class pallet creates a rectangular block, which is easy to effectively protect with stretch film. For Class B units, the individual load layers may differ in dimensions. The stretch film protection is still effective, but the film is more exposed to puncture. Class C pallet units are formed from packages of various shapes and are the least susceptible to being protected by foil [3].

During the transportation, even under the normal operating conditions, inertial forces act on the loading unit, what may cause displacement of individual packages, deformation of the unit treated as a solid and, in extreme cases, its disintegration. This problem occurs in all the modes of transport [4-6]. Stability, or also called rigidity, of the load unit is defined in literature and in transport safety standards as the integrity of the packages included in the unit and keeping unchanged shape [7]. Accidents involving trucks are very often caused by inadequate load securing [8-9]. Suitably rigid and properly secured against shifting in the vehicle's cargo space load unit improved human safety and protects products against damage. This problem has been noticed in the European Union, which has issued Directive 2014/47 [10].

The load unit stability is checked by experimental methods. Simple static tilt tests on an inclined plane or dynamic impact tests are carried out. Standard EUMOS 40509 recommends conducting dynamic tests [11]. Because real life truck braking tests are too expensive, they are carried out on special mobile platforms accelerated and braked. Typical laboratory stand is equipped with a fast camera for documenting the load's behavior and sensors measuring forces between packaging and film. The results of such tests depend not only on the stretch film performance and wrapping methods, but also on the weight and dimensions of the packages, friction coefficients and on packages arrangement pattern on the pallet [12]. Rationalizing film consumption, based on dynamic tests, requires at least several trials to be performed and is therefore time consuming.

The properties of the stretch film can vary widely and depend largely on the materials used and the production

Tomasz Matyja

Faculty of Transport and Aviation Engineering, Silesian University of Technology, Katowice, Poland

E-mail of corresponding author: tomasz.matyja@polsl.pl 


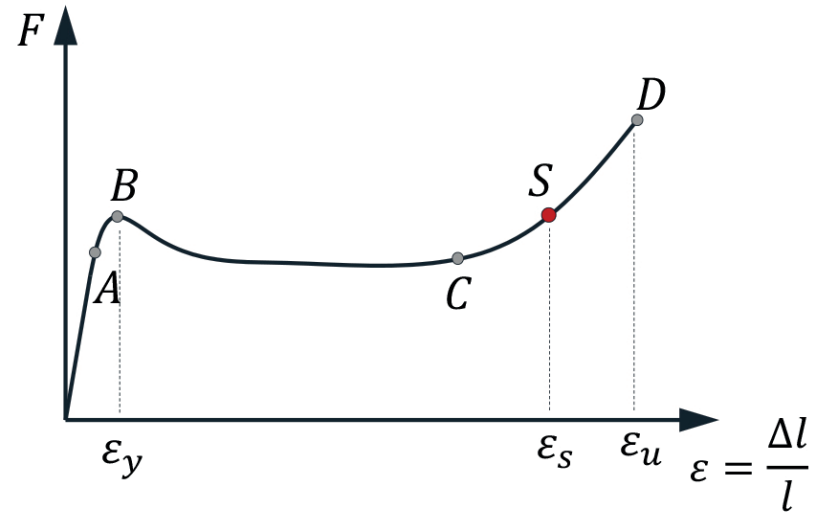

a)

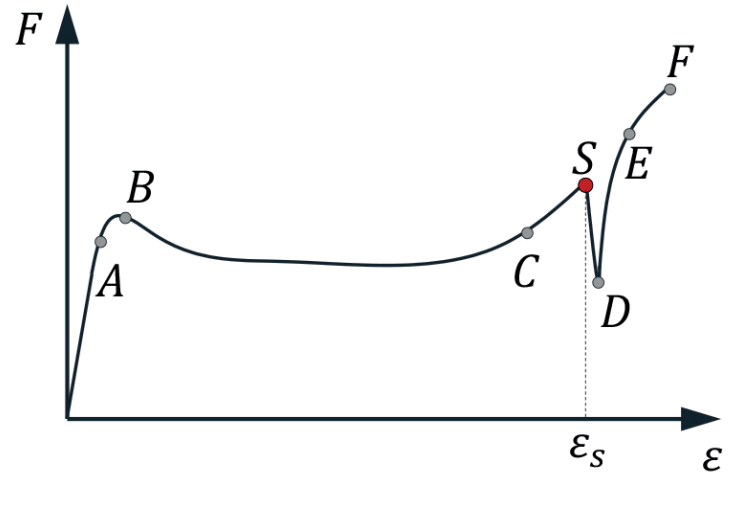

b)

Figure 1 The stretch film tensile tests: a) determining the sweet spot (sweet spot stretch level $\boldsymbol{\varepsilon}_{s} \approx 0.75 \boldsymbol{\varepsilon}_{u}, \boldsymbol{\varepsilon}_{u}-$ ultimate stretch), b) interruption of the tensile test to allow the stress relaxation

technology. Any change of the film distributor usually requires new braking tests. For this reason, it is important to search for effective calculation methods to estimate the necessary number of film layers to ensure the load stability.

The simple simulation model of a loading unit secured with stretch film is presented below. This model is adapted to class A pallet with a layered structure. Performing the simulation requires collecting several experimental data. Among others, measurements of the stretch films strength properties are necessary. However, such tests are much cheaper and faster than the acceleration tests.

\section{Basic properties of the stretch film}

The stretch film is the most effective and efficient packaging material. The specific properties of the stretch film, such as: significant elongation of $400 \%$ and a certain type of shape memory - elastic recovery, result from its layered structure. Usually, the foil sheet is made of a few to several layers. Polyethylene and vinyl-based plastics, such as PVC, LDPE, EVA, LLDPE, are used for the film production. The final properties of the film depend on the selection of the above-mentioned materials and the production process and can be significantly variable.

A number of tests are performed to determine the properties of the film: classical ultimate tensile test; retention test, which measures the maximum load holding force and reduction in force over time; puncture test, which measures the maximum force required to puncture the film; cling test, which measures ability of a film to stick to itself at a selected pre-stretch level; quality test a selected stretch level, which checks homogeneity of the film along its length based on the measurement of the current stretch at a constant tensile force [13].

The stretch film tensile tests indicate that the film behaves like a hyper elastic body. On a typical graph obtained from a tensile test can be distinguished: linear elastic region, yield stress, necking and strain hardening region (Figure 1.a). The test is carried out in accordance with the direction of winding the film on the roll (MD - Machine Direction). The results obtained for the perpendicular direction (CD - Cross Machine Direction or Transverse Direction) are usually different.

Pre-stretching of film in the load wrapping process should be planned so as to reach the strain hardening zone, on the rising part of the tensile test graph. In technical jargon this point is referred to as a "sweet spot" [14]. Usually this point corresponds to a strain between $200 \%$ and $350 \%$. By pre-stretching the film, an adequate value for the containment force is obtained. An additional positive effect of the pre-stretching is less film consumption. Based on the value of the tensile force at the sweet spot and the slope of the ascending part of the tensile graph, the approximate relationship between the containment force and the current stretch of the film can be determined as:

$F_{C} \approx F_{S}+\left.\frac{d F}{d(\Delta l)}\right|_{\Delta l S}\left(\Delta l-\Delta l_{S}\right)$,

where $F_{S}, \Delta l_{S}$ - the initial value of the containment force and the elongation corresponding to the sweet spot, respectively. The derivative value (curve slope) can be considered as the spring stiffness.

Stresses in the stretch film relax very quickly and decrease by up to $50 \%$. Therefore, some authors recommend interrupting the tensile test after reaching the sweet spot for one hour and then continue until the film breaks [2]. Thanks to this procedure, both the initial value of the containment force and the slope of the graph are closer to reality (Figure 1.b).

\section{Equations of motion}

The problem of investigation of the dynamics of packages forming the load unit is a complex issue of the multi-body contact (MBS) with friction [15]. The solution of this problem is complicated by the interaction between the 


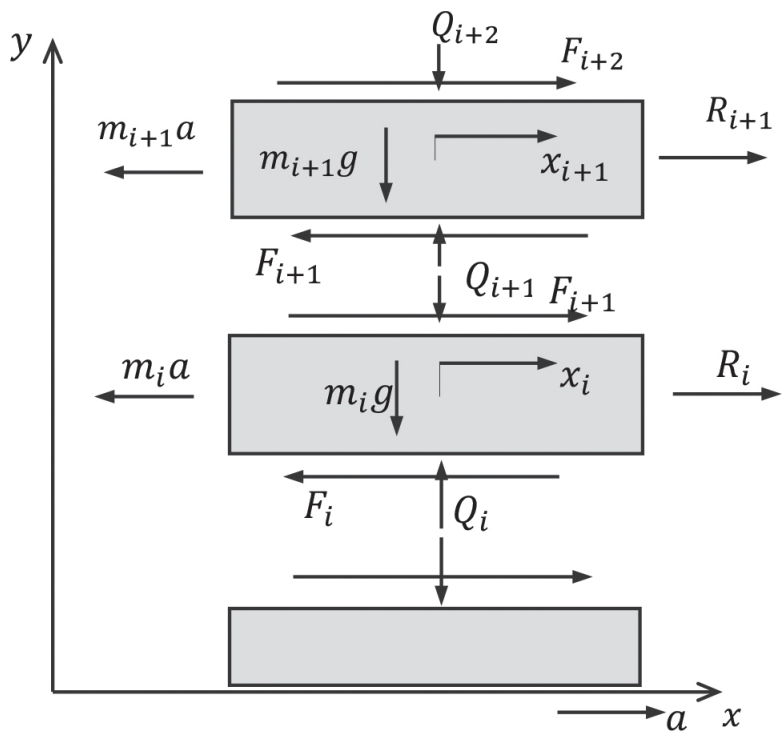

Figure 2 Free body diagram of the load layers

practically massless stretch film and packages. One way to consider the stretch film in the load unit model is to replace it with a cloud of equidistant points connected by springs of known stiffness [16]. At each step of simulation, both the positions of the packages relative to each other and the packages relative to the point cloud should be controlled. This type of simulation requires considerable computing power and is time consuming.

The paper proposes a simplified model of a class A pallet load unit, which has a layered structure. The assumption of a layered structure simplifies the model and means that the layers can only move horizontally with respect to each other.

Based on the free body diagram of the load layers (Figure 2), equations of motion of the individual layers can be written in the form:

$$
\begin{aligned}
& m_{i} \ddot{x}_{i}=-m_{i} a-F_{i}+F_{i+1}+R_{i}, i=1, \ldots, N \\
& F_{N+1}=0,
\end{aligned}
$$

where:

$m_{i}$ - mass of the layer,

$a$ - acceleration of the global system (vehicle cargo space),

$F_{i}$ - friction force between layer $i$ and $i-1$,

$R_{i}$ - the resultant reaction (restoring) force of the stretch film acting on the layer (appears from the containment force and film tensions),

$x_{i}$ - displacement of the layer $i$ relative to the global system.

The proposed layered model of the loading unit takes into account only the horizontal displacement of the layers. This is sufficient when the purpose of the simulation is to choose the appropriate value of the containment force. If the containment force is insufficient or the load is not wrapped in the film, one or more adjacent layers may lose their stability due to significant displacements. Therefore, the simulation stops automatically when it detects a loss of stack stability when the center of gravity of the top or several subsequent top layers extend beyond their base. This particular case is shown in the Figure 7.

The issue of the stacked block stability is well known from elementary physics [17]. The condition of continuing the simulation can be written as the following product of logical expressions:

$\prod_{k=0}^{N-1}\left[\left|\frac{\sum_{i=N-k}^{N} m_{i} x_{i}}{\sum_{i=N-k}^{N} m_{i}}-x_{N-k-1}\right|<\frac{L}{2}\right]=1$,

where $L$ - is the length of the load layers.

\section{$4 \quad$ Friction force modeling}

The slip-stick friction was considered in the model. The friction force is defined by Equation [18]:

$$
F_{i}\left(\Delta \dot{x}_{i}, F_{i}^{\text {input }}\right)=\left\{\begin{array}{cc}
F_{i}^{\text {stick }}\left(F_{i}^{\text {input }}\right) & \left|\Delta \dot{x}_{i}\right|<V_{\text {break }}, \\
F_{i}^{\text {slip }}\left(\Delta \dot{x}_{i}\right) & \left|\Delta \dot{x}_{i}\right| \geq V_{\text {break }}
\end{array}\right.
$$

where:

$\Delta \dot{x}_{i}=\dot{x}_{i}-\dot{x}_{i-1}-$ it is the speed of layer " $i$ " with respect to the layer located below, $V_{\text {break }}$ - is the velocity of the layers breaking.

When the relative velocity of the layers is lower than the assumed very low speed of the break $\left|\Delta \dot{x}_{i}\right|<V_{\text {break }}$ then stick occurs and the force of static friction should be determined from the condition of balance of the upper layer relative to the lower one:

$F_{i}^{\text {stick }}\left(F_{i}^{\text {input }}\right)=\left\{\begin{array}{cl}-F_{i}^{\text {break }} \operatorname{sign}\left(F_{i}^{\text {input }}\right) & \left|F_{i}^{\text {input }}\right|>F_{i}^{\text {break }} \\ F_{i}^{\text {input }} & \left|F_{i}^{\text {input }}\right| \leq F_{i}^{\text {break }}\end{array}\right.$

where:

$F_{i}^{\text {break }}=\mu_{s i} Q_{i}$ is the maximum static friction value, $\mu_{s i}, Q_{i}$ - are the static friction coefficient and normal force between the surfaces of the layer " $i$ " and " $i-1$ ", respectively. 


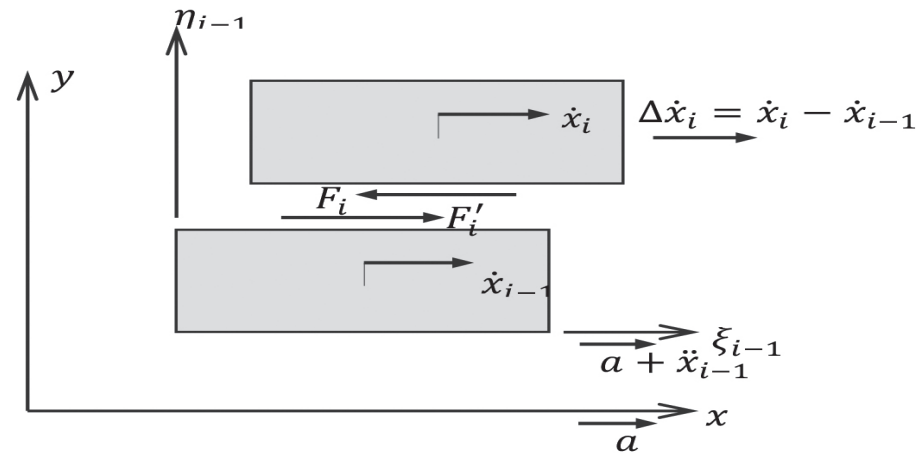

Figure 3 The local non-inertial coordinate system for determining the stick friction force
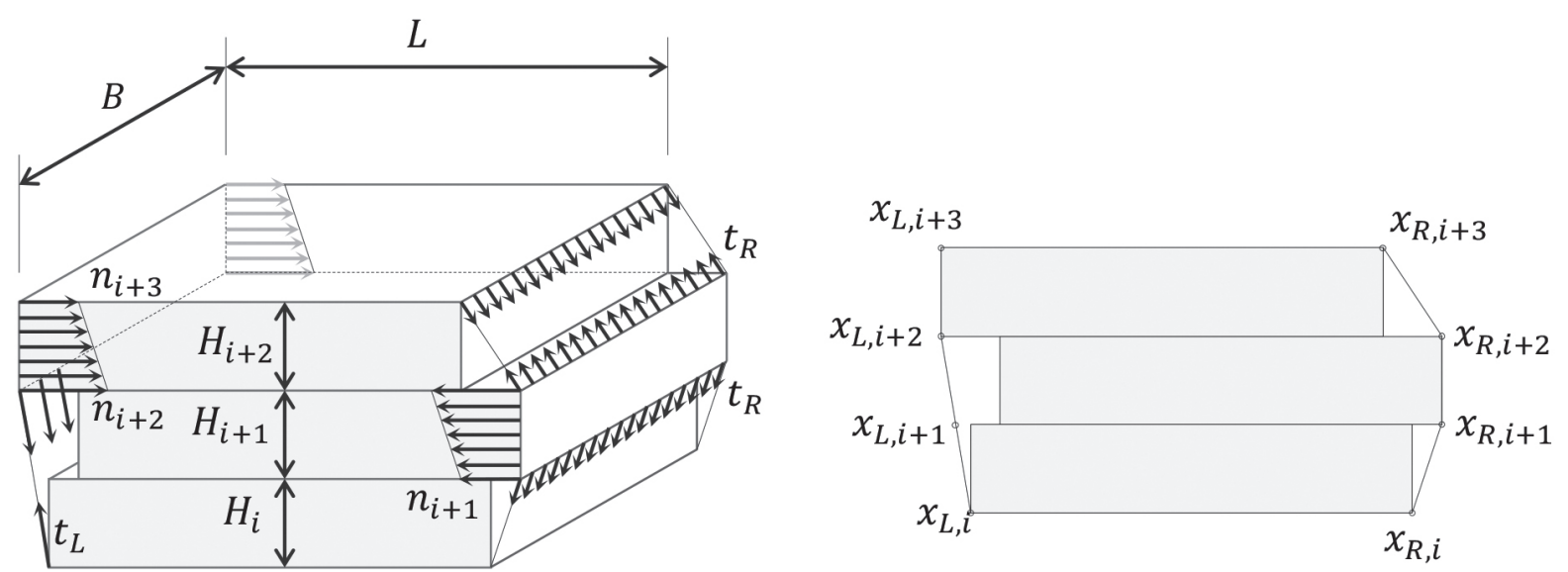

Figure 4 Assumed tensions distributions in the stretch film as a result of mutual displacement of the load layers and control points on the edge of the foil

The force $F_{i}^{\text {input }}$ can be determined from the equilibrium equation of a layer " $i$ ", which is temporarily at rest, relative to the layer " $i$ - 1 ", i.e. in a non-inertial system moving with acceleration $a+\ddot{x}_{i-1}$ (Figure 3):

$F_{i}^{\text {input }}=-m_{i}\left(a+\ddot{x}_{i-1}\right)+F_{i+1}+R_{i}, i=N, \ldots, 1$,

To determine the force $F_{i}^{\text {input }}$ one must know the friction force $F_{i+1}$ from the upper layer. The task is statically determined. However, the process of calculating the value of the friction force must take place from top to bottom.

In the case of slip $\left|\Delta \dot{x}_{i}\right| \geq V_{\text {break }}$, the friction force is determined from Equation [19]:

$$
\begin{aligned}
& F_{i}^{\text {slip }}\left(\Delta \dot{x}_{i}\right)=\sqrt{2 e}\left(F_{i}^{\text {break }}-F_{i}^{\text {coulomb }}\right) . \\
& \cdot \exp \left[-\left(\frac{\Delta \dot{x}_{i}}{V_{\text {stribeck }}}\right)^{2}\right] \frac{\Delta \dot{x}_{i}}{V_{\text {stribeck }}}+, \\
& +F_{i}^{\text {coulomb }} \tanh \left(\frac{\Delta \dot{x}_{i}}{V_{\text {coulomb }}}\right)+f \Delta \dot{x}_{i},
\end{aligned}
$$

where:

$F_{i}^{\text {coulomb }}=\mu_{k i} Q_{i}$ - kinetical friction force,

$\mu_{k i}$ - kinetical friction coefficient between layers " $i$ " and " $i$ - 1",

$V_{\text {stribeck }}$ - speed threshold of the Stribeck phenomenon,

$V_{\text {coulomb }}$ - Coulomb speed threshold,

$f$ - viscous friction coefficient.
The hyperbolic tangent in Equation (7) guarantees the continuity of the friction force when the relative velocity passes through zero. In the model it was assumed that [19]:

$$
V_{\text {stribeck }}=\sqrt{2} V_{\text {break }} \quad V_{\text {coulomb }}=0.1 \cdot V_{\text {break }},
$$

\section{$5 \quad$ Restoring force modeling}

A two-dimensional problem was considered. Mobile control points have been introduced on both sides of the film, which are always at the same height regardless of the vertical stretching of the film. These points correspond to boundaries of the layers. In Figure 4 the edges of the deformed foil are visible in the form of polylines. The control points on the left and right of the palette are also shown.

To determine the position of the film, relative to the displaced layers of cargo, a simple recursive algorithm for subsequent stretch film tension was proposed. Algorithm does not require solving the contact problem. The foil, represented by the control points, is stretched successively to the most protruding vertices of the packages. The adopted algorithm requires additional simplifying assumptions. Friction between the foil and the load was omitted. Due to that, it can be assumed that the film is uniformly tensioned in the vertical direction. This tension results from the 


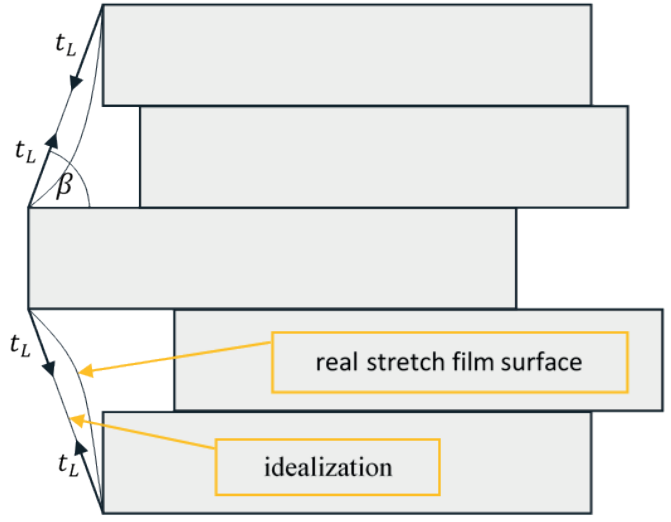

Figure 5 Additional forces acting on layers due to the vertical stretching of the film

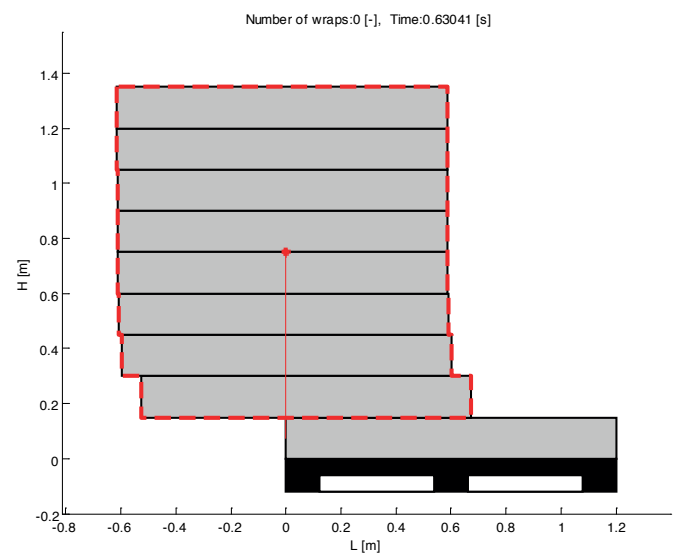

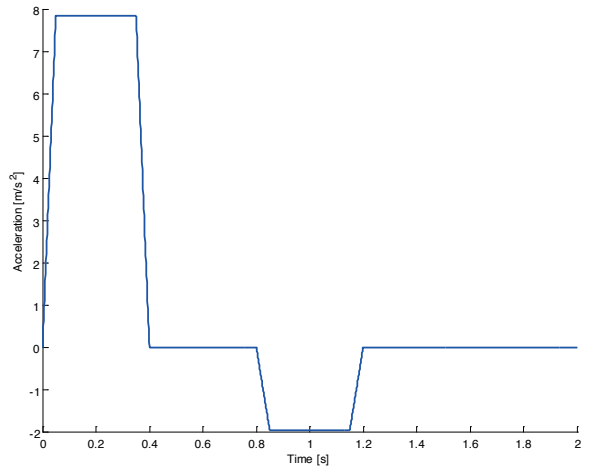

Figure 6 Acceleration graph during the emergency braking test

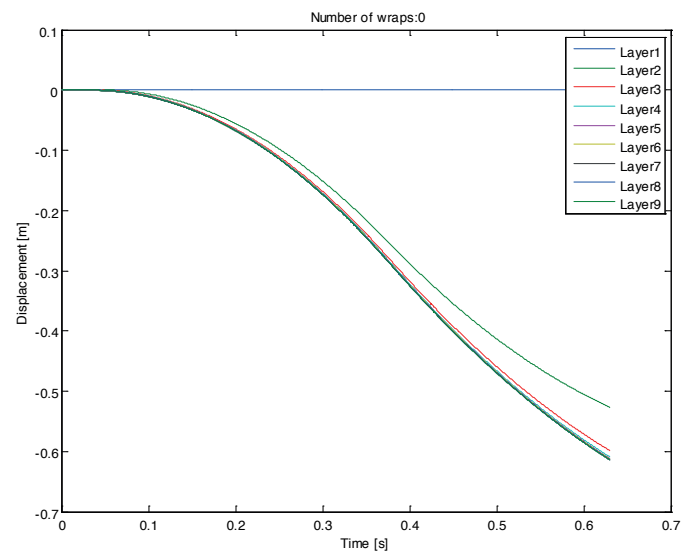

Figure 7 Displacements of unsecured layers

current length of the polyline, whose vertices are the control points. The curvature of the foil between the control points was also omitted (Figure 5). The operation of the algorithm explains the following pseudo code:

\section{StretchFoilOverPoints(StartPoint, EndPoint)}

$\{\quad$ FindPoint $=\{$ Find the node of the rectangle representing the layer of cargo located furthest on the left (right) side relative to the current position of the left (right) polyline representing the foil edge\};

\section{If exist FindPoint}

$\{$ Move the left (right) polyline nodes to stretch the foil on the nodes: (StartPoint, FindPoint, EndPoint);

StretchFoilOverPoints(StartPoint, FindPoint); StretchFoilOverPoints(FindPoint, EndPoint); \}

When the load is undeformed, the film pressure acts evenly on all sides. After the load layers have moved, the pressure distribution changes. The foil now presses on the most shifted layers of charge. When the layer moves away from the edge of the film, the pressure quickly decreases to zero. However, when the layer presses against the edge of the film, an additional pressure increase occurs as a result of stretching the film in the horizontal direction.
The horizontal film tension force per unit of length at selected control points can be expressed by formula:

$n_{i}=n_{0}+k_{H}\left(x_{R i}-x_{L i}-L\right)$,

where:

$n_{0}$ - tensile force obtained initially in the wrapping process (containment force),

$k_{H}$ - horizontal stiffness of the wrapped film,

$x_{L i}(t), x_{R i}(t)$ - coordinates of the foil control points on the left-hand and right-hand side.

Similarly, the vertical force of film stretching per unit length on the left- (right-hand) side of the loading unit is

$t_{L(R)}=t_{0}+k_{v}\left(\sum_{i=1}^{N} l_{L(R) i}-H\right)$,

where:

$t_{0}$ - pre-tension of the film due to wrapping,

$k_{v}$ - vertical film stiffness,

$l_{L(R) i}$ - distance between the control points on the left (right) side.

The individual layers are affected by the resultant force due to the film tensions. Part of the force from the horizontal tension of the film can be expressed by formula: 

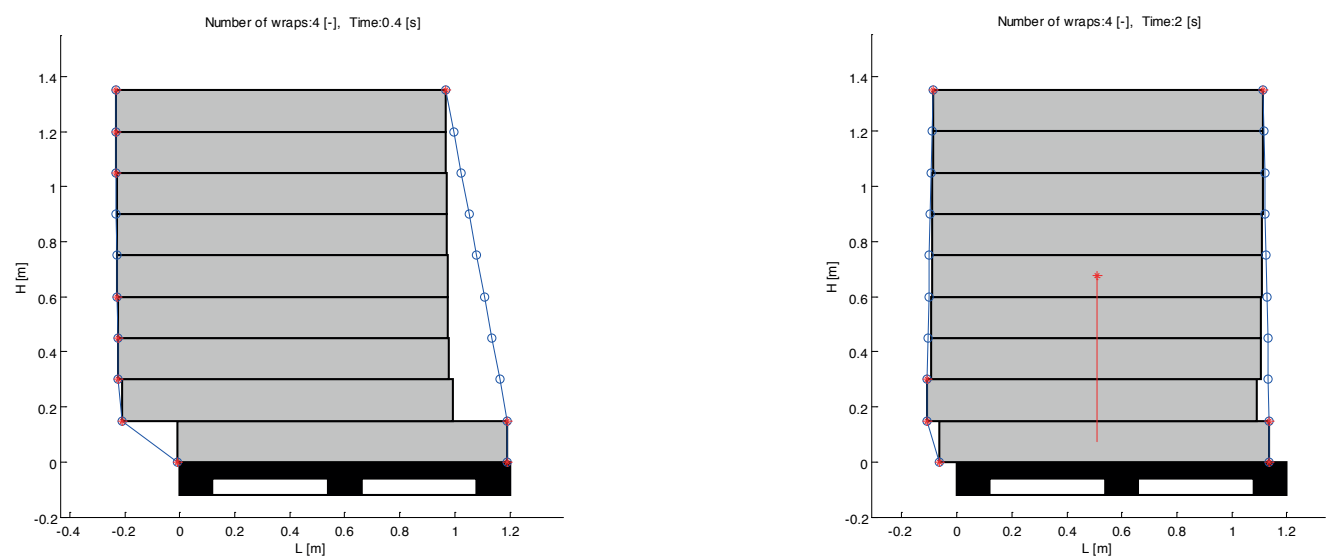

Figure 8 Deformation the of loading unit (first variant of wrapping)
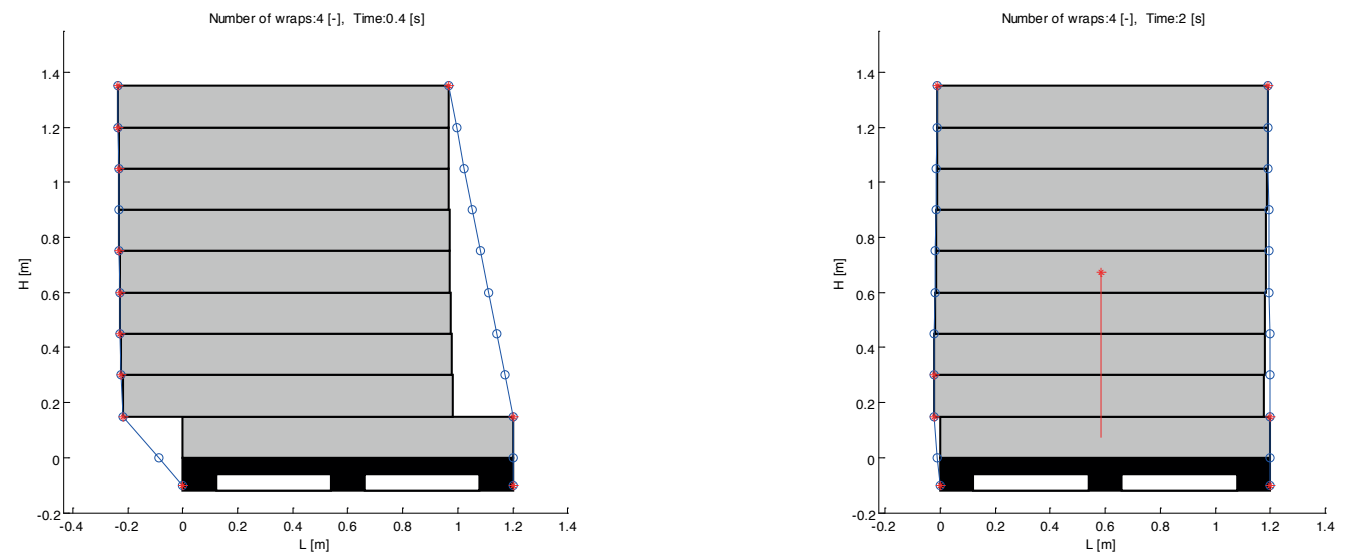

Figure 9 Deformation the of loading unit (second variant of wrapping)
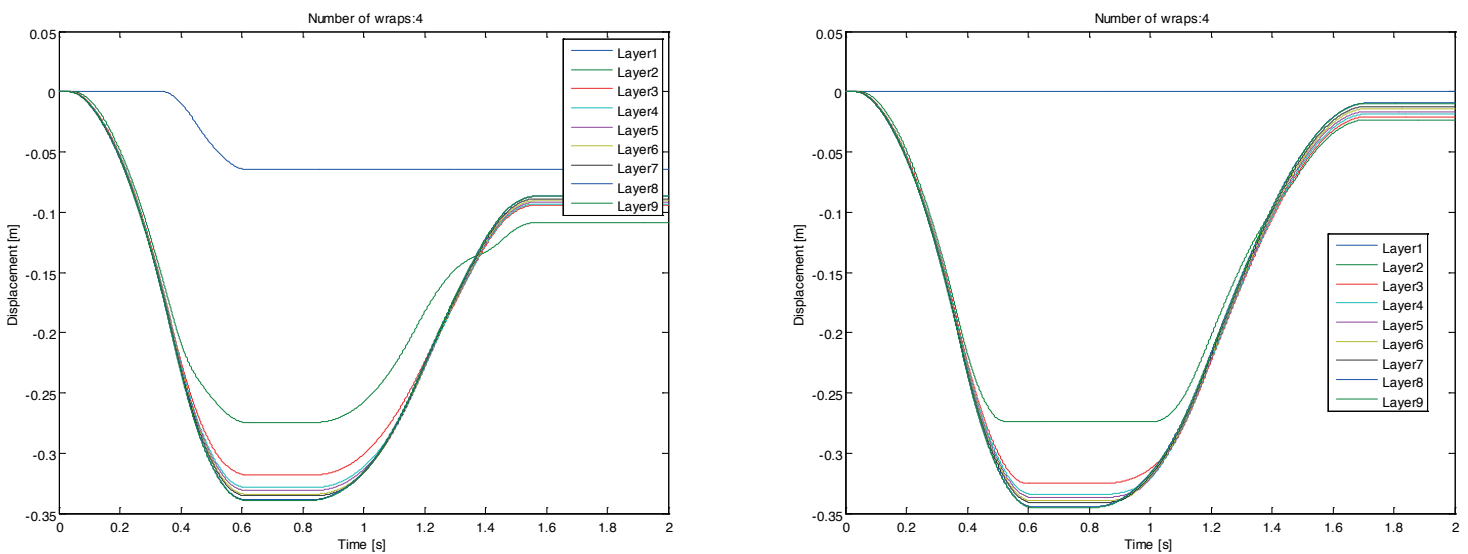

Figure 10 Comparison of the displacements of layers ( 4 wraps, variant 1 left and variant 2 right)

$$
\begin{gathered}
R_{i}=2 n_{0} H_{i}\left\{\exp \left[\alpha\left(\frac{x_{i}-\min _{i=1: N}\left(x_{i}\right)}{\Delta}\right)^{2}\right]-\exp \left[\alpha\left(\frac{\max \left(x_{i}\right)-x_{i}}{\Delta}\right)\right]\right\} \\
+\left\{\begin{array}{c}
\left(n_{p}+n_{p+1}-n_{0}\right) H_{p} \quad x_{L p}=x_{L p+1}=x_{p}=\min _{i=1: N}\left(x_{i}\right) \\
-\left(n_{q}+n_{q+1}-n_{0}\right) H_{q} \quad x_{R q}=x_{R q+1}=x_{q}=\max _{i=1: N}\left(x_{i}\right) \\
0
\end{array}\right.
\end{gathered}
$$

where: $H_{i}$ - layer height,

$\alpha$ - dimensionless containment force vanishing factor (e.g. $\alpha=\ln 0.01$ )

$\Delta$ - assumed distance of the containment force disappearance. 

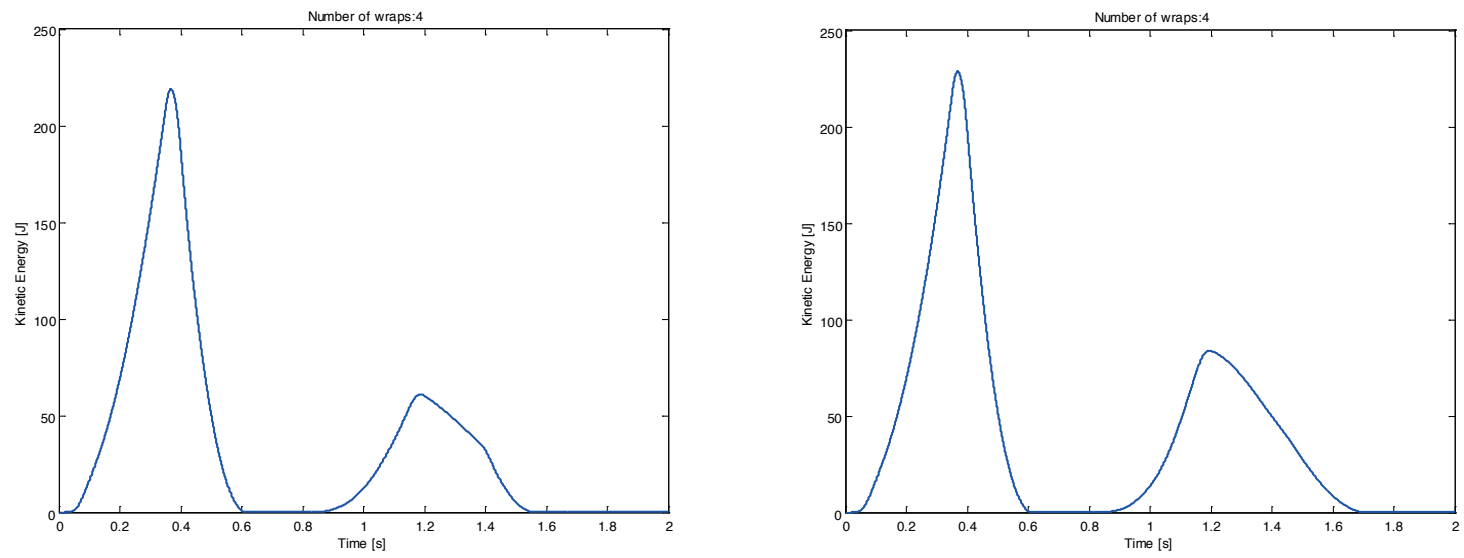

Figure 11 Comparison of the total kinetic energy ( 4 wraps, variant 1 left and variant 2 right)
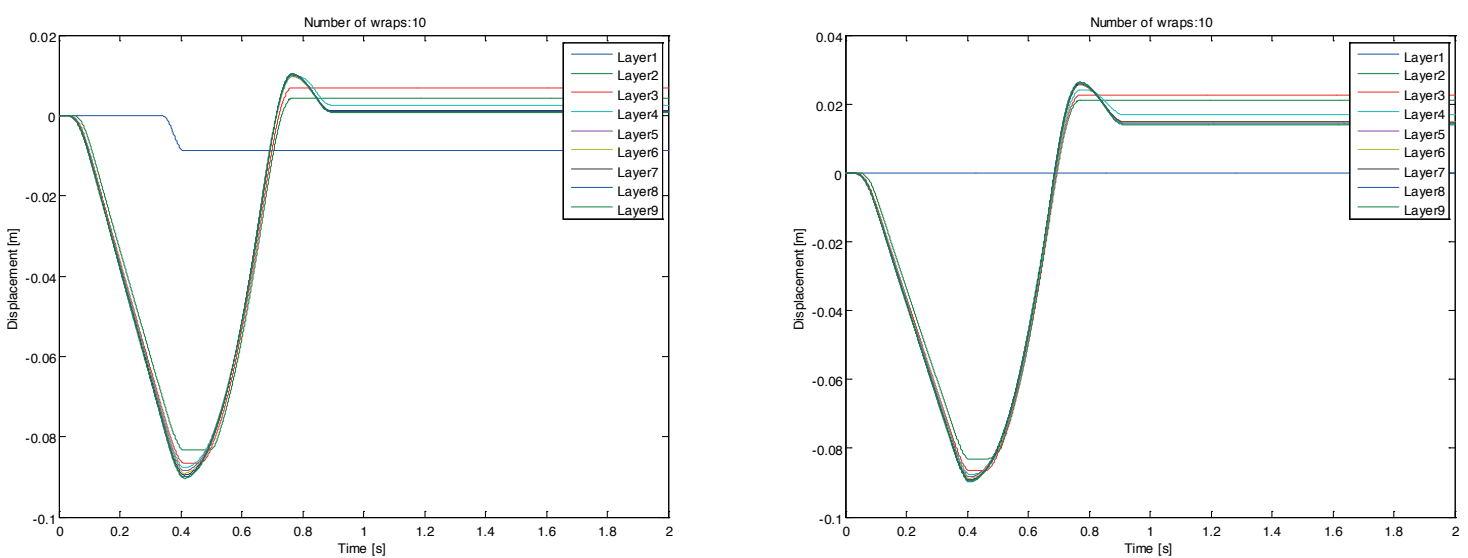

Figure 12 Comparison of the displacements of layers (10 wraps, variant 1 left and variant 2 right)
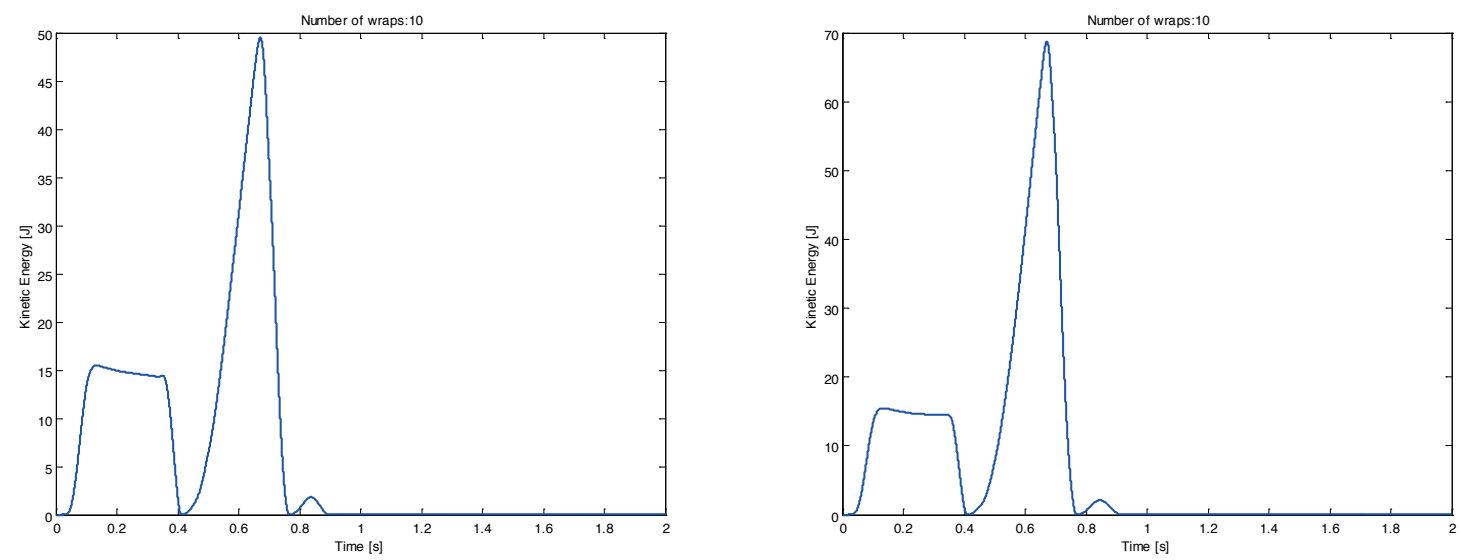

Figure 13 Comparison of the total kinetic energy (10 wraps, variant 1 left and variant 2 right)

Horizontal projections of forces caused by the vertical tension of film will additionally modify values of the restoring forces. However, the vertical projections will change the value of normal forces and consequently also the friction forces (Figure 4).

The containment force and required stiffnesses of the stretch film can be estimated from the film tensile tests, pre-stretching level and number of wraps. The containment force can be also measured [20].

\section{Examples of simulation results}

The mathematical model described above has been implemented in Matlab environment. In most cases, the differential equations were solved numerically using a standard ode 45 solver and an automatically chosen variable time step. However, it has been observed that when the containment force is much higher than necessary and it significantly limits the movement of the load layers, 

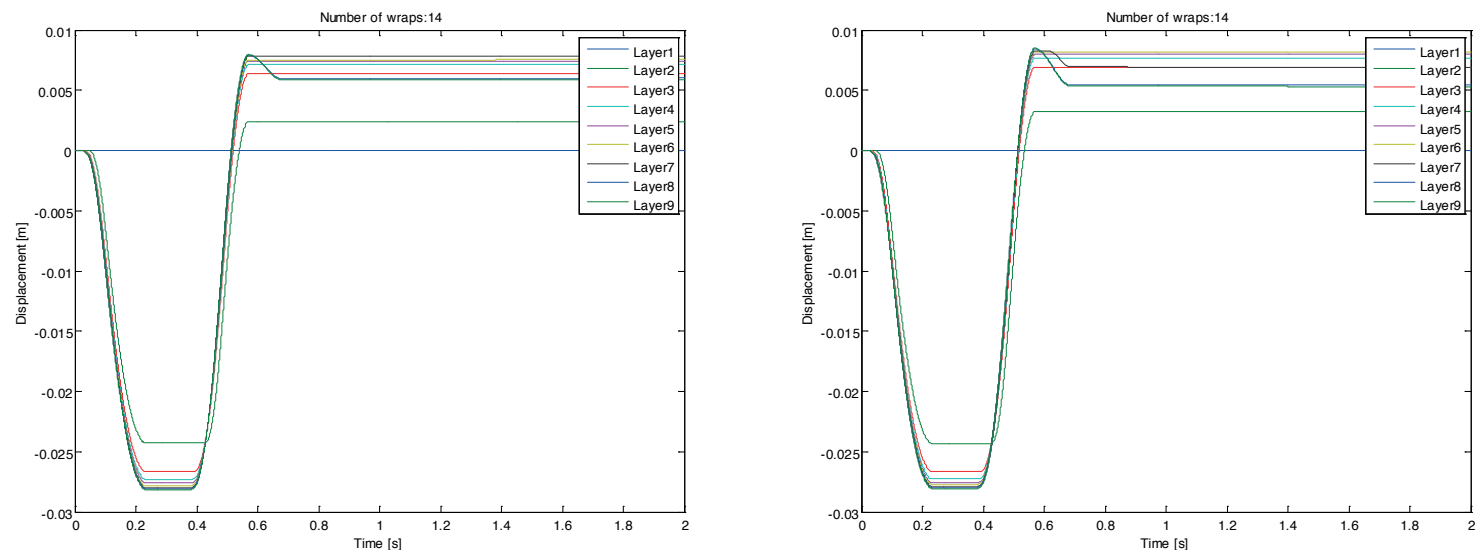

Figure 14 Comparison of the displacements (14 wraps, variant 1 left and variant 2 right)
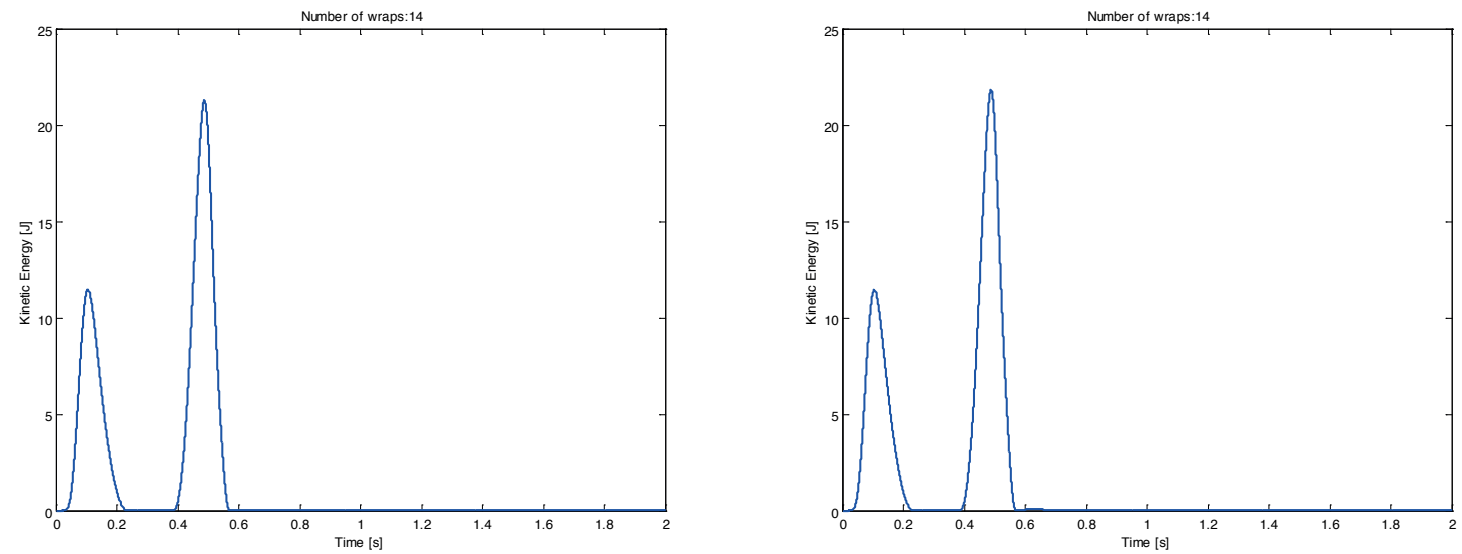

Figure 15 Comparison of the total kinetic energy (14 wraps, variant 1 left and variant 2 right)
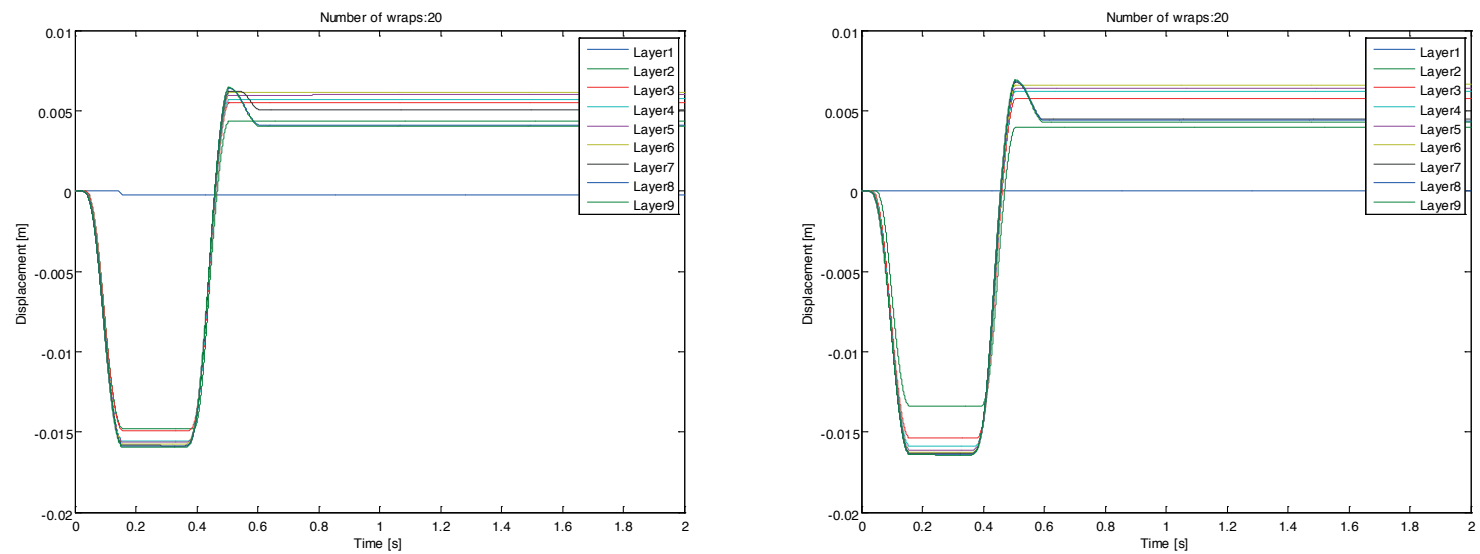

Figure 16 Comparison of the displacements (20 wraps, variant 1 left and variant 2 right)

the time of numerical calculations increases rapidly. In this case, solvers dedicated to stiff problems are much more effective.

The test was carried out in accordance with EUMOS guidelines. These types of tests are usually carried out in real conditions using special mobile platforms [21]. Emergency braking of a vehicle transporting a load unit with retardation of $0.8 \mathrm{~g}$ during the first $400 \mathrm{~ms}$ and next acceleration of $0.2 g$ was simulated (Figure 6).
A medium heavy unit made of 9 identical layers was considered. The length and height of the layer were $1.2 \mathrm{~m}$ and $0.15 \mathrm{~m}$, respectively. The layer weight $50 \mathrm{~kg}$. The coefficient of kinetic friction between layers was equal 0.3 , while between layer and pallet 0.4 . To model the Stribeck effect, it was assumed that the coefficient of increase in friction force is equal $120 \%$ and breakaway speed is equal $10^{-5} \mathrm{~m} / \mathrm{s}$. The coefficient of viscous friction was assumed to be equal to $20 \mathrm{Ns} / \mathrm{m}$. The containment 
force per wrap and per unit length was equal $85 \mathrm{~N} / \mathrm{m}$. Assumed distance of the containment force disappearance was $0.02 m$.

Figure 7 shows the visualization and values of the layers displacements if the cargo is unsecured with stretch film. The simulation stops automatically when it detects a loss of stack stability when the center of gravity of the top or several subsequent top layers extend beyond their base.

Wrapping the load four times with foil reduces the layer displacement. However, the loading unit is significantly deformed in the braking phase. Two variants were analyzed: the first when only the load is wrapped and the second when the pallet is also partially wrapped. Figures 8 and 9 visualize the deformation of the unit at the end of the emergency braking and at the end of the simulation test in both variants of wrapping. Comparison of displacement values (Figure 10) and total kinetic energies (Figure 11) does not allow to clearly determine which of the wrapping methods is better. Wrapping layers of packaging together with the pallet means that the final displacement of the load on the pallet is smaller and the bottom layer does not move. However, there is no doubt that the number of layers of stretch film is too small.

A simulation was then carried out in the case of wrapping the load with stretch film ten times. The results of both wrapping options are comparable. However, in the first variant the final displacement of the layers is slightly smaller (Figure 12). This is done at the expense of slightly shifting the first layer relative to the pallet. In addition, the peak of kinetic energy in the second phase of motion is smaller in the first variant, which is visible in the energy diagrams (Figure 13). Increasing the number of wraps to fourteen means that the results are practically identical in both variants (Figures 14 and 15).

Further increasing the number of wraps to twenty makes no sense, because it does not significantly improve the results (Figure 16). It can be considered that a load unit wrapped fourteen times is sufficiently stable.

\section{Conclusions}

The model of dynamics of the load unit, secured with the stretch film, presented in the paper is greatly simplified due to assumed layered structure and the method of modeling the impact of film on packages. If the load on the pallet is stacked in columns or on bricks, then obtained results can be treated only as a rough approximation of reality. The model guarantees more accurate results when the layer is one package or panel.

The smaller the range of movements performed by the layers, the higher the stability (also called rigidity) of the load unit. Of course, rigidity in the context of solid mechanics will never be achieved. At the same time, the smaller the displacements, the more accurate the method of determining the force of the package's interaction with the stretch film. Because the main purpose of the simulation was to estimate the value of the containment force (or the number of film layers if initial pre-stretching is known) guaranteeing the stability of the loading unit, the proposed model seems to be sufficiently effective. The goal is not to accurately determine the displacement of individual layers if the stability is not achieved.

Wrapping the load together with the pallet is a common practice. Studies have shown that this effectively blocks the movement of the bottom layer, but it is not strictly necessary to ensure the stability of the loading unit. More important is how many layers of film were used. This note applies when there is increased friction between the bottom layer of the load and the pallet.

It was also noted that there is a certain limit quantity of the stretch film wraps beyond which the results will no longer improve. This is the basis for optimizing the stretch film consumption.

The numerical investigation suggests that a good measure of the load unit stability assessment can be the maximum kinetic energy generated as a result of movement of individual layers. The lower kinetic energy, the better the load protection and stability.

\section{References}

[1] WHITE, M. S, HAMNER, P. Pallets move the world: the case for developing system-based designs for unit load. Forest Product Journal. 2005, 55, p. 8-16. ISSN 0015-7473.

[2] BISHA, J. Correlation of the elastic properties of stretch film in unit load containment. Ph.D. dissertation. Virginia Tech, Blacksburg, VA, USA: Virginia Tech, Wood Science and Forest Products, 2012.

[3] DUNNO, K. D., WYNS J., COOK, J. Evaluation of containment force variability between different grades of stretch film. International Journal of Advanced Packaging Technology [online]. 2017, 5(1), p. 267-274. eISSN 2349-6665. Available from: https://doi.org/10.23953/cloud.ijapt.318

[4] CIESLA, M., OPASIAK, T. Load securing in cargo transport units. Katowice: PAN, 2014.

[5] FIGLUS, T., KUCZYNSKI, L. Selection of a semi-trailer for the haulage of long oversize loads, taking into account an analysis of operational damage. In: 2018 XI International Science-Technical Conference Automotive Safety: proceedings. IEEE. ISBN 978-1-5386-4578-9.

[6] SKRUCANY, T., SEMANOVA, S., KENDRA, M., FIGLUS, T., VRABEL, J. Measuring mechanical resistances of a heavy good vehicle by coastdown test. Advances in Science and Technology-Research Journal [online]. 2018, 12(2), p. 214221. ISSN 2299-8624. Available from: https://doi.org/10.12913/22998624/91889 
[7] SINGH, J., SAHA, K., SEWELL, T.: Evaluation of stability of unit loads for tilt and shock events during distribution. Journal of Applied Packaging Research [online]. 2017, 9(3), p. 73-93. ISSN 1557-7224. Available from: https://scholarworks.rit.edu/japr/vol9/iss3/5

[8] SKRUCANY, T., GNAP, J. The effect of the crosswinds on the stability of the moving vehicles. Applied Mechanics and Materials [online]. 2014, 617, p. 296-301. ISSN 1662-7482. Available from: https://doi.org/10.4028/www.scientific.net/ AMM.617.296

[9] FEDORKO, G., MOLNAR, V., HONUS, S., NERADILOVA, H., KAMPF, R. The application of simulation model of a milk run to identify the occurrence of failures. International Journal of Simulation Modelling [online]. 2018, 17(3), p. 444457. ISSN 1726-4529, eISSN 1996-8566. Available from: http://doi.org/10.2507/IJSIMM17(3)440

[10] Directive 2014/47/EU of the European Parliament and of the Council on the technical roadside inspection of the roadworthiness of commercial vehicles circulating in the Union [online] [Viewed 2016-12-16]. Available from: https://publications.europa.eu

[11] EUMOS 40509-2012: Test method for load unit rigidity [online] [Viewed 2019-12-16]. Available from: https://eumos.eu/ quality-standards

[12] FINNEMORE, D. Stretch wrap film and pallet load stability. Powder and Bulk Engineering [online]. 2017, 5, [accessed 2019-12-16]. ISSN 0897-6627. Available at https://www.powderbulk.com/enews/2017/editorial/story_pdf/ pbe_04_19_17rihf.pdf

[13] ASTM D4649-03. Standard guide for selection and use of stretch wrap films. West Conshohocken, PA, USA: American Society for Testing and Materials (ASTM) International, 2016.

[14] BP-Film-Testing [online] [Viewed 2019-12-16]. Available from: https://www.bestpackaging.com/wp-content/ uploads/2018/02/ BP-Film-Testing.pdf

[15] FEDORKO, G., IVANCO, V., MOLNAR, V., HUSAKOVA, V. Simulation of interaction of a pipe conveyor belt with moulding rolls. Procedia Engineering [online]. 2012, 48, p. 129-134. ISSN 1877-7058. Available from: http://doi.org/10.1016/j.proeng.2012.09.495

[16] DANJOU, S., OSTERGAARD, N. Application of computational MBD for simulation of wrap packaging performance. Journal of Applied Packaging Research [online]. 2018, 10(3), p. 25-36. ISSN 1557-7224. Available from: https://scholarworks.rit.edu/japr/vol10/iss3/3

[17] HALL, J. F. Fun with stack blocks. American Association of Physics [online]. 2005, 73(12), p. 1107-1116. ISSN 0002-9505, eISSN 1943-2909. Available from: https://doi.org/10.1119/1.2074007

[18] PENNESTRI, E., ROSSI, V., SALVINI, P., VALENTINI, P. P. Review and comparison of dry friction force models. Nonlinear Dynamics [online]. 2016, 83(4), p. 1785-1801. Available from: https://doi.org/10.1007/s11071-015-2485-3

[19] MATLAB documentation. Friction in contact between moving bodies [online] [Viewed 2019-12-16]. Available from: https://www.mathworks.com/ref/translationalfriction

[20] The transportable test pallet [online] [Viewed 2019-12-16]. Available from: https://www.bestpackaging.com.au/

[21] Pallet stability testing - ESTL [online] [Viewed 2019-12-16]. Available from: https://s3-eu-west-1.amazonaws.com/upload 